\title{
A Study on the User Acceptance of O2O Services : Mediating Effect of Customer Attitude
}

\author{
Ji Bok CHUNG ${ }^{1}$, Sung Jip NAM ${ }^{2}$ \\ 1 First Author Professor, Department of Retail Management, Kongju National University, South Korea. \\ E-mail: jbchung@kongju.ac.kr \\ 2 Corresponding Author Associate Professor, Department of Business Administration, Hannam University, South Korea. \\ E-mail: sjnam@hnu.kr
}

Received: 11 August 2020. Revised: 25 August 2020. Accepted: 09 September 2020

\begin{abstract}
Purpose - New technologies allow service providers to integrate all the customer information within and between contact channels so that they can offer individualized services. The availability of new mobile devices enables retailers to interact with customers through countless channels (Rigby, 2011). The objective of this research is to examine customers' attitudes toward $\mathrm{O} 2 \mathrm{O}$ (on-line to off-line) services and their intention to use based on the Technology Acceptance Model (TAM).
\end{abstract}

Research design, data, and methodology - Utilizing the TAM model, the mediating effect of the users' attitudes toward $\mathrm{O} 2 \mathrm{O}$ services on the relationship among perceived ease of use, perceived usefulness, perceived risks and intention to use are to be investigated.

Results - The result shows that the perceived ease of use, perceived usefulness, perceived risks have a significant effect on customers' attitudes toward $\mathrm{O} 2 \mathrm{O}$ services. It is also revealed that the attitude toward $\mathrm{O} 2 \mathrm{O}$ services has a mediating effect among perceived ease of use, perceived usefulness, perceived risks and intention to use.

Conclusions - The boundary between on-line and off-line is eroding and various services based on the $\mathrm{O} 2 \mathrm{O}$ platform are growing. The results of this study and managerial implications can be applied to O2O platform operators or enterprises planning to sharp on their competitiveness edge through offering variations of service channels.

Keywords: O2O services, Omni-channel retailing, TAM

JEL Classification Code: L81, M15, M31.

(c) Copyright: The Author(s)

This is an Open Access article distributed under the terms of the Creative Commons Attribution Non-Commercial License (http://Creativecommons.org/licenses/by-nc/4.0/) which permits unrestricted noncommercial use, distribution, and reproduction in any medium, provided the original work is properly cited. 


\section{Introduction}

New technologies allow service providers to integrate all the customer information within and between contact channels. In addition to traditional brick and mortal stores, service providers also equip on-line channels as a supplement of purchasing places. The availability of new mobile devices and touch-ups as well as off-line channels have transformed the consumer buying process. No matter how the shoppers swap across channels and devices, the use of various channels and touch-points are able to be consistent, concurrent and compatible (Verhoef, Kannan \& Inman, 2015). Digital retailing is evolving so differently that it has a new label, omnichannel retailing. It enables retailers to interact with customers through countless channels (Rigby, 2011). The advantages of digital retailing are increasing as technology is evolving as well as the availability of multi-channels.

$\mathrm{O} 2 \mathrm{O}$ stands for "on-line to off-line" or "off-line to on-line" and it is used to describe a variety of e-commerce services that provide on-line information, services, or discounts to consumers which enhances their off-line shopping experience. $\mathrm{O} 2 \mathrm{O}$ services have experienced explosive growth and are expanding into diverse areas by fusing with existing service concepts (Oh, 2016). In 2017, Alibaba launched a digitized physical supermarket chain, Hema, where shoppers use a mobile app for on-line orders and in-store purchases of groceries or freshly prepared foods. Shoppers may purchase on-line products while shopping in-store and pay digitally or with facial recognition. Hema deliveries are fulfilled by the store in as fast as 30 minutes within a three-kilometer radius.

The objective of this research is to examine customers' attitudes toward $\mathrm{O} 2 \mathrm{O}$ (on-line to off-line) services and their intention to use the new type of services based on the Technology Acceptance Model (TAM). Though the consistency of the TAM model is well discussed, some researchers still question the role of the perceived usefulness and the perceived ease of use variables in the model ( $\mathrm{Wu} \& \mathrm{Lu}, 2013)$. Further, Ashraf, Thongpapanl and Auh, (2014) reported that that the overall predictive power of the TAM variables is robust. Yet, the importance of perceived usefulness or perceived ease of use variables depend on development of business stages. Thus, it is important to validate the applicability of TAM in a new business case, such as the $\mathrm{O} 2 \mathrm{O}$ format.

The remainder of this paper is organized as follows. Research background and literature reviews are provided in section two. Literature on TAM and $\mathrm{O} 2 \mathrm{O}$ services will be discussed. In section three, a research model is presented based upon the literature. Hypotheses are developed from the literature as well. In section four, we provide the survey results using qualitative analysis. Concluding remarks and managerial implications of the research are provided in section five.

\section{Literature Review}

\subsection{Technology Acceptance Model}

The User Acceptance Model of technology has been an important field of research over a number of decades. Based upon prior research by Fishbein and Ajzen (1970), Davis $(1985,1989)$ proposed the TAM, which explains that the user's system use is influenced by motivation of the use of the system, in turn, is directly influenced by the actual system's features and capabilities. Davis (1985) suggested that user's motivation of using technology can be explained by three variables: perceived ease of use (PEOU), perceived usefulness (PU), and attitude toward using (AT). Later he focused on only two distinctive variables, PU and PEOU, as sufficient enough to predict an individual's attitude on use of a system. Over the years TAM has evolved into a leading model in predicting and explaining technical system usage. Research on technology acceptance is still ongoing (Chuttur, 2009)

Table 1: Application of the TAM

\section{Variations in TAM application}

Applications

E-mail, voice mail, fax, dial-up system, e-commerce application, group ware, word processor, spread sheet, presentation software, data base program, case tools, hospital IS, Decision support systems, Expert support system, and telemedicine technology 


\begin{tabular}{|c|l|}
\hline Country & $\begin{array}{l}\text { USA, UK, Taiwan, Hong Kong, Swiss, Japan, Australia, Turkey, Canada, Kuwait, } \\
\text { Nigeria, France, Singapore, China and Finland }\end{array}$ \\
\hline Type of Study & Lab study, Field study and Web surveys \\
\hline Participants & $\begin{array}{l}\text { Students (undergraduates and graduates), knowledge workers, physicians, bank, } \\
\text { managers, programmer analysists, IT vendor specialists, computer programmers, } \\
\text { internet users, brokers and sales assistants }\end{array}$ \\
\hline
\end{tabular}

Source: Chuttur, (2009)

Davis, Bagozzi and Warshwa (1989) tested the TAM model to conduct a longitudinal study. They found that both the PU and the PEOU were found to have direct influence on the intention to use (ITU) of the system. With more than 700 citations, Davis's research (1989) has adapted and expanded to various fields and to many ways (Chuttur, 2009). Most of these researches show significant statistical soundness for the high influence of PU on behavioral ITU of the system.

\subsubsection{Variables and their definitions within the TAM}

\section{Perceived Ease of Use (PEOU)}

PEOU can be defined as the degree to which the prospective user expects that trusting a particular system would be free of physical and mental effort (Davis, 1985).

\section{Perceived Usefulness (PU)}

PU can be defined as the degree to which an individual believes that using a specific system will enhance his or her job or life performance (Davis, 1985). PU may be also influenced by PEOU because the easier the system is to use the more useful it can be if other things being equal.

\section{Perceived Risks (PR)}

The PR is a consumer's subjective uncertainty about the profit or loss (Mitchell, Davies, Moutinho \& Vassos, 1999). The PR in using O2O service is not only the quality of the purchased products, but also the lack of reliability that may appear in the purchasing process (Lim \& Kim, 2018). Consumers are faced with different types of risk such as physical risk, performance risk, social risk, psychological risk, financial risk, time risk, and lost opportunity (Maciejewski, 2011). If consumers' PR is high, consumers tend to refrain from purchasing in order to to minimize perceived risk.

\section{Attitude toward new technology (AT)}

Attitude is an expression of an individual's positive and negative feelings about performing the actual behavior whether consumers like it or not. According to the Theory of Reasoned Action (Ajzen \& Fishbein, 1975), consumer attitude influences consumer purchase behavior and behavior is determined by intentions, which are also influenced by attitudes and subjective norms.

\section{Intention to Use (ITU)}

Intention is a motivating factor that affects a person's behavior and a conscious and active area of man (Ajzen, 2011). The relationship between attitude and intentions to use has been widely examined and supported empirically (Spears \& Singh, 2004).

\subsection{Applicability of TAM to different environment}

Empirical adoption seems to be subjective across industry-specific and across groups of customers. It has led researchers to consider whether TAM utilized model acceptance would be similar across different cultures (McCoy, Galletta \& King 2007). In addition, applicability of the TAM model across all cultures has also been doubted. Further $\mathrm{Wu}$ and $\mathrm{Lu}$ (2013) have proposed that the role of the PU and the PEOU variables in the TAM model is still unclear. Thus, for e-retailers or $\mathrm{O} 2 \mathrm{O}$ retailers who try to reach more customers from on and off-line purchases, it is 
important to have a comprehensive understanding of the TAM's applicability in an $\mathrm{O} 2 \mathrm{O}$ environment. Ashraf et al., (2014) report that the overall predictive power of the TAM variables is robust. However, researchers have reported that the importance of the PU and the PEOU variables have different magnitudes depending on the stage of adoption (Davis, Bagozzi \& Warshaw, 1989). When customers are familiar with the business, the PU variable is more directly and indirectly related with intention to purchase. However, when they are not familiar with the business, the PEOU variable is more strongly related with the purchase of the intention. Thus, it is important to validate the applicability of TAM in the case of new types of services, such as $\mathrm{O} 2 \mathrm{O}$ format.

\subsection{TAM research in $\mathrm{O} 2 \mathrm{O}$ Services}

Zhang (2013) defines $\mathrm{O} 2 \mathrm{O}$ transactions as commercial transactions in which on-line and off-line transactions are connected, fused and mutually influencing. Oh (2016) analyze the effects of consumer innovativeness and selfefficacy on different age groups' acceptances and diffusion of innovative technology specialized in food delivery service. Chi, Kang, Han and Choi. (2016) examine consumers' perception about O2O commerce and the effects to that discontinuance intention of the services. Kim and Lee (2016) examine the consumer acceptance of automobilerelated $\mathrm{O} 2 \mathrm{O}$ services utilizing the TAM. Yim and Han (2016) investigate the ITU of omni-channel services by applying the TAM model. They show that the PEOU and the PU has significant effect on ITU and using omnichannel has a significant effect on brand-customer relationships. Lee and Yang (2017) demonstrate that on-line quality system and perceived price of off-line quality had a positive effect on user satisfaction and that user satisfaction had a positive effect on intention to reuse. Lee and Jeon (2017) categorized the characteristics of O2O services and analyzed the mediating effect of safety related with the customer satisfaction. An, Lee and Suh, (2018) investigated the motivation factor and the relationships between users' loyalty to $\mathrm{O} 2 \mathrm{O}$ services. Wenjie and Moon (2019) tried to identify the factors that influence consumer re-use on $\mathrm{O} 2 \mathrm{O}$ services based on the theory of motivation model.

\section{Research Methods and Materials}

\subsection{Research Model and Hypotheses}

We adopted the TAM (Davis, 1995) as a research framework. The objective of current research is to examine the customers' attitude toward $\mathrm{O} 2 \mathrm{O}$ services and their intention to use based on the TAM. Based on the literature, we developed the following hypotheses in order to validate the mediating effect of the attitude toward $\mathrm{O} 2 \mathrm{O}$ services on the relationship among PEOU, PU, PR and ITU are to be investigated.

We adopted the TAM (Davis, 1995) as a research framework. The objective of current research is to examine the customers' attitude toward $\mathrm{O} 2 \mathrm{O}$ services and their intention to use based on the TAM. From the literature, we developed the following hypotheses in order to validate the mediating effect of the attitude toward $\mathrm{O} 2 \mathrm{O}$ services on the relationship among PEOU, PU, PR and ITU are to be investigated.

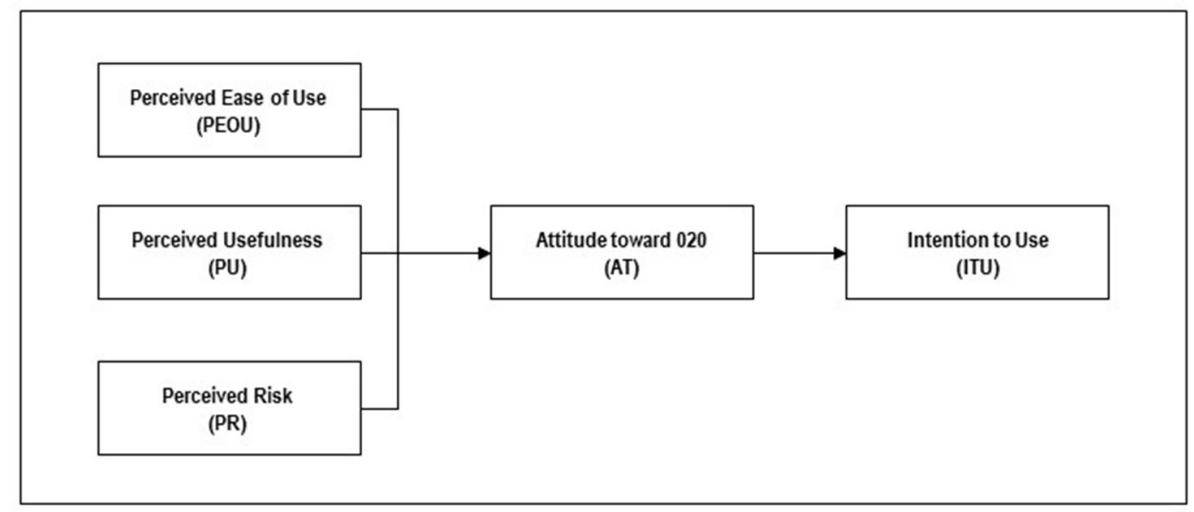

Figure 1: Research Model 
H1: PEOU has a positive impact on Attitude toward O2O services.

H2: PU has a positive impact on Attitude toward O2O services.

H3: PR has a negative impact on Attitude toward $\mathrm{O} 2 \mathrm{O}$ services.

H4: Attitude toward $\mathrm{O} 2 \mathrm{O}$ services has a mediating effect between PEOU and ITU

H5: Attitude toward O2O services has a mediating effect between PU and ITU

H6: Attitude toward O2O services has a mediating effect between PR and ITU

\subsection{Survey Questionnaire and Data Collection}

We conducted a survey to the target of 200 respondents to validate the proposed hypotheses. The survey consisted of questions related to TAM variables, perceived ease of use (four items), perceived usefulness (four items), perceived risks (four items), attitudes (four items), intention to use (four items). Survey items were adopted from existing literature (Lee \& Lin, 2005; Parasuraman et al., 2005). All items were measured on a five-point Likert scale by values ranging from five (strongly agree) to one (strongly disagree). Statistical analyses were conducted using SPSS 24. After excluding incomplete or unfaithful questionnaires, 185 samples were analyzed in our study in Table 2 for demographic analysis. The demographic profile of respondents is as shown.

\subsection{Demographic Analysis}

Among the respondents, the total number of men accounts for $110(59.5 \%)$ while the number of women accounts for $75(40.5 \%)$. Of the respondents, $85 \%$ of them have experience of O2O services, while $15 \%$ of them do not. About $50 \%$ (49.7\% to be exact) of respondents are from the age group of 29 or under. And the age group of 30 to 39 accounts for $22.2 \%$. The age group of 50 or over accounts for just $11.9 \%$. Considering the population target for the research is those who have experience in $\mathrm{O} 2 \mathrm{O}$ services, which are relatively new types of business, the above figure seems to be reasonable and well represented.

From the respondent's group, the most prevalent $\mathrm{O} 2 \mathrm{O}$ service type is food delivery $(69,37.3 \%)$. The subsequent frequencies are mobility $(37,20 \%)$, which accounts for $20.0 \%$. Mobile payment $(27,14.6 \%)$, accommodations (19, $10.3 \%)$, and mobile coupon (16, 8.6\%) comes respectively.

Table 2: Demographic Profile $(\mathrm{n}=185)$

\begin{tabular}{|c|c|c|c|c|c|}
\hline Gender & $\mathbf{n}$ & $\%$ & Age & $\mathbf{n}$ & $\%$ \\
\hline Male & 110 & 59.5 & under 29 & 92 & 49.7 \\
\hline Female & 75 & 40.5 & $30 \sim 39$ & 41 & 22.2 \\
\hline Experienced & $\mathrm{n}$ & $\%$ & $40 \sim 49$ & 30 & 16.2 \\
\hline Yes & 157 & 85.0 & \multirow{2}{*}{ over 50} & \multirow{2}{*}{22} & \multirow{2}{*}{11.9} \\
\hline No & 28 & 15.0 & & & \\
\hline Income $(10,000 \mathrm{KRW})$ & $\mathbf{n}$ & $\%$ & O20 Service Experience & $\mathbf{n}$ & $\%$ \\
\hline$\sim 100$ & 51 & 27.6 & Mobile Coupon & 16 & 8.6 \\
\hline $100 \sim 199$ & 44 & 23.8 & Food Delivery & 69 & 37.3 \\
\hline $200 \sim 299$ & 37 & 20.0 & Accommodations & 19 & 10.3 \\
\hline $300 \sim 399$ & 25 & 13.5 & Mobile Payment & 27 & 14.6 \\
\hline $400 \sim 499$ & 11 & 5.9 & Mobility & 37 & 20.0 \\
\hline over 500 & 17 & 9.2 & Etc & 17 & 9.2 \\
\hline
\end{tabular}




\section{Results}

\subsection{Reliability and Validity}

SPSS 24 statistical software is utilized to analyze the data from the respondents. We conduct exploratory factor analysis to check whether the respondent group keeps the same structure of components of variables as the literate provides. The initial factor structure of the respondents has shown a relatively similar construct as TAM. None of the individual items have shown weak correlation with the variables. Thus, we proceed to the next stage of factor analysis. Confirmatory factor analysis using principal component analysis is performed and details are displayed in Table 3. The adequacy of factor analysis is confirmed by the KMO (Kaiser-Meyer-Olkin) index which was 0.896 . KMO values between 0.7-0.8 are considered as good, between 0.8-0.9 are great, and above 0.9 are superb (Field, 2005). So, we can be confident that the confirmatory factor analyses from the data set is adequate. Further, factor loadings of individual items are over 0.6. So, we can tell that variables in this research consist with relatively well represented items. For the reliability verification, the values of Construct Reliability (C.R.) and Average Variance Extracted (AVE) are calculated. According to the data in Table 3, the values of all five variables exceeded over 0.6. Thus, the reliability and convergent validity seem to be appropriate (Fornell \& Larcker, 1981).

Table 3: Confirmative Factor Analysis

\begin{tabular}{|c|c|c|c|c|c|c|c|c|c|}
\hline Variables & $\begin{array}{c}\text { Measure- } \\
\text { ment }\end{array}$ & $\begin{array}{c}\text { Factor } \\
\text { Loading }\end{array}$ & $\begin{array}{l}\text { Eigen } \\
\text { value }\end{array}$ & $\begin{array}{l}\text { Var } \\
(\%)\end{array}$ & Mean & S.E. & C.R & $\begin{array}{c}\text { Cronbach } \\
\text { alpha }\end{array}$ & AVE \\
\hline \multirow{4}{*}{ AT O2O } & atti2 & 0.845 & \multirow{4}{*}{7.46} & \multirow{4}{*}{41.48} & 3.86 & .714 & \multirow{4}{*}{0.85} & \multirow{4}{*}{0.891} & \multirow{4}{*}{0.58} \\
\hline & atti4 & 0.803 & & & 3.76 & .757 & & & \\
\hline & atti1 & 0.777 & & & 3.79 & .757 & & & \\
\hline & atti3 & 0.605 & & & 3.40 & .803 & & & \\
\hline \multirow{4}{*}{ PEOU } & peou2 & 0.830 & \multirow{4}{*}{1.87} & \multirow{4}{*}{10.39} & 3.97 & .791 & \multirow{4}{*}{0.84} & \multirow{4}{*}{0.865} & \multirow{4}{*}{0.586} \\
\hline & peou3 & 0.822 & & & 4.07 & .834 & & & \\
\hline & peoul & 0.732 & & & 4.11 & .789 & & & \\
\hline & peou4 & 0.644 & & & 3.92 & .869 & & & \\
\hline \multirow{3}{*}{ PU } & pul & 0.815 & \multirow{3}{*}{1.59} & \multirow{3}{*}{8.85} & 3.96 & .790 & \multirow{3}{*}{0.82} & \multirow{3}{*}{0.915} & \multirow{3}{*}{0.60} \\
\hline & pu2 & 0.757 & & & 3.96 & .757 & & & \\
\hline & pu3 & 0.750 & & & 4.04 & .727 & & & \\
\hline \multirow{3}{*}{ ITU } & inten5 & 0.848 & \multirow{3}{*}{1.25} & \multirow{3}{*}{6.96} & 2.98 & .851 & \multirow{3}{*}{0.82} & \multirow{3}{*}{0.806} & \multirow{3}{*}{0.61} \\
\hline & inten4 & 0.803 & & & 3.46 & .835 & & & \\
\hline & inten3 & 0.687 & & & 3.76 & .842 & & & \\
\hline \multirow{3}{*}{ PR } & risk4 & 0.807 & \multirow{3}{*}{1.06} & \multirow{3}{*}{5.87} & 3.03 & 1.014 & \multirow{3}{*}{0.80} & \multirow{3}{*}{0.742} & \multirow{3}{*}{0.57} \\
\hline & risk3 & 0.798 & & & 2.82 & .992 & & & \\
\hline & risk1 & 0.649 & & & 2.97 & .872 & & & \\
\hline
\end{tabular}

Table 4: Correlation Analysis between Variables

\begin{tabular}{|c|c|c|c|c|c|c|}
\hline & PU & PEOU & PR & AT & ITU & AVE \\
\hline PU & 1 & $.623^{* *}$ & $-.327^{* *}$ & $.630^{* *}$ & $.473^{* *}$ & 0.588 \\
\hline PEOU & - & 1 & $-.214^{*}$ & $.570^{* *}$ & $.377^{* *}$ & 0.572 \\
\hline PR & - & - & 1 & $-.369^{* *}$ & $-.250^{* *}$ & 0.618 \\
\hline AT O2O & - & - & - & 1 & $.543^{* *}$ & 0.637 \\
\hline ITU & - & - & - & - & 1 & 0.629 \\
\hline
\end{tabular}

$* \mathrm{p}<.05, * * \mathrm{p}<.01$ 
The discriminant validity of the research model is tested by comparing correlation and the value of AVE in Table 4. Due to the square roots of all AVE are greater than correlation values, the discriminant validity of all variables seems to be acceptable.

\subsection{Hypotheses Tests}

\subsubsection{Analysis of Direct Effects} 5 .

The direct effects between variables are analyzed using multiple regression and the results are displayed in Table

Table 5: Direct effects between variables

\begin{tabular}{|c|c|c|c|c|c|c|c|c|}
\hline $\begin{array}{l}\text { Dependent. } \\
\text { Variable } \\
\end{array}$ & $\begin{array}{c}\text { Independent } \\
\text { Variable } \\
\end{array}$ & B & S.E & $\boldsymbol{\beta}$ & $\mathbf{t}$ & $\mathbf{p}$ & Tolerance & VIF \\
\hline \multirow{5}{*}{$\begin{array}{l}\text { Attitude toward } \\
\qquad \mathrm{O} 2 \mathrm{O}\end{array}$} & (constant) & 1.581 & .366 & & 4.31 & .000 & & \\
\hline & PEOU & .274 & .077 & .288 & 3.57 & .001 & .611 & 1.64 \\
\hline & $\mathrm{PU}$ & .367 & .078 & .391 & 4.69 & .000 & .572 & 1.75 \\
\hline & PR & -.151 & .056 & -.179 & -2.68 & .008 & .893 & 1.12 \\
\hline & \multicolumn{8}{|c|}{$\mathrm{R} 2=0.477, \mathrm{D} . \mathrm{W}=2.0$} \\
\hline \multirow{3}{*}{ Intention to Use } & (constant) & 1.215 & .297 & & 4.09 & .000 & & \\
\hline & $\begin{array}{c}\text { Attitude toward } \\
\mathrm{O} 2 \mathrm{O}\end{array}$ & .590 & .079 & .543 & 7.46 & .000 & & \\
\hline & \multicolumn{8}{|c|}{$\mathrm{R} 2=0.295, \mathrm{D} . \mathrm{W}=2.096$} \\
\hline
\end{tabular}

\subsubsection{Analysis of Indirect Effects}

The indirect effects are tested using a percentile bootstrap estimation approach with 5000 samples, implemented with the PROCESS macro Version 3 (Hayes, 2017). According to the data provided in Table 6, Indirect effect was significant for $\mathrm{PU}(\mathrm{B}=.156, \mathrm{SE}=.059, \mathrm{LCI}=.055, \mathrm{UCI}=.285), \mathrm{PEOU}(\mathrm{B}=.116, \mathrm{SE}=.047, \mathrm{LCI}=.037, \mathrm{UCI}$ $=.221)$ and $\mathrm{PR}(\mathrm{B}=-0.064, \mathrm{SE}=.030, \mathrm{LCI}=-0.132, \mathrm{UCI}=-0.013)$. From the indirect analyses, we can conclude that all attitudes toward $\mathrm{O} 2 \mathrm{O}$ services have mediation effects. Therefore, we found that hypotheses $<\mathrm{H} 4>,<\mathrm{H} 5>$, $<$ H6 $>$ are supported.

Table 6: Direct and Indirect effects between variables

\begin{tabular}{|c|c|c|r|r|r|}
\hline Variable & \multicolumn{2}{|c|}{ Effect } & Boot SE & \multicolumn{1}{c|}{ Boot LLCI } & Boot ULCI \\
\hline \multirow{3}{*}{ PEOU } & Total & .138 & .100 & -.061 & .336 \\
\cline { 2 - 6 } & Direct & .022 & .099 & -.176 & .219 \\
\cline { 2 - 6 } & Indirect & .116 & .047 & .037 & .221 \\
\hline \multirow{3}{*}{ PU } & Total & .362 & .102 & .159 & .564 \\
\cline { 2 - 6 } & Direct & .206 & .105 & -.002 & .414 \\
\cline { 2 - 6 } & Indirect & .156 & .059 & .055 & .285 \\
\hline \multirow{3}{*}{ PR } & Total & -.097 & .074 & -.243 & .049 \\
\cline { 2 - 6 } & Direct & -.036 & .072 & -.175 & .110 \\
\cline { 2 - 6 } & Indirect & -.064 & .030 & -.132 & -.013 \\
\hline
\end{tabular}

The results of above hypotheses tests are summarized in table 7. 
Table 7: Results of Hypotheses

\begin{tabular}{|ll|l|}
\hline \multicolumn{1}{|c|}{ Hypotheses } & Results \\
\hline H1: & Perceived ease of use has positive impact for Attitude toward O2O services. & Accepted \\
\hline H2: & Perceived usefulness has positive impact for Attitude toward O2O services. & Accepted \\
\hline H3: & Perceived risks have negative impact for Attitude toward O2O services. & Accepted \\
\hline H4: & $\begin{array}{l}\text { Attitude toward O2O services has mediating effect between perceived ease of use and } \\
\text { intention to use }\end{array}$ & Accepted \\
\hline H5: $\quad \begin{array}{l}\text { Attitude toward O2O services has mediating effect between perceived usefulness and } \\
\text { intention to use }\end{array}$ & Accepted \\
\hline H6: & $\begin{array}{l}\text { Attitude toward O2O services has mediating effect between perceived risks and intention } \\
\text { to use }\end{array}$ & Accepted \\
\hline
\end{tabular}

\section{Conclusion}

The boundary between on-line and off-line is eroding and various services based on the $\mathrm{O} 2 \mathrm{O}$ platform are growing rapidly. This study investigates the current state of $\mathrm{O} 2 \mathrm{O}$ services usage and technology acceptance attitude using the TAM (technology acceptance model). The objective of this research is to examine customers' attitudes toward $\mathrm{O} 2 \mathrm{O}$ (on-line to off-line) services and their intention to use the new type of services based on the model. Davis et al., (1989) demonstrate that both the PU and the PEOU are found to have direct influence on intention to use (ITU) of the system within the model. However, Wu \& Lu (2013) have proposed that the role of the PU and the PEOU variables is still unclear. Researchers have reported that the importance of the PU and the PEOU variables have different magnitudes depending on the stage of adoption. Even further, applicability of the TAM model across all cultures has also been doubted (McCoy, 2007).

Thus, this research is performed to validate the role of the PEOU and the PU in the TAM in O2O services circumstance. As $\mathrm{O} 2 \mathrm{O}$ services is relatively a new type of business, it will be beneficial to both academia and business practitioners to to validate how customers perceive and show their attitude to the new type of retail channel. Our findings from the research is as follows. First, our results show that the PEOU, PU, PR have significant effects on the attitude toward $\mathrm{O} 2 \mathrm{O}$ services. So, though $\mathrm{O} 2 \mathrm{O}$ services is relatively a new business type, applicability of TAM in the industry across-culture seem to be robust. Second, Davis et al., (1989) suggests that when customers are familiar with the business, the PU variable is more directly and indirectly related with intention to purchase, however when they are not familiar with the business, the PEOU variable is more strongly related with the purchase of the intention. Our research result indicates that the PEOU variable has higher magnitude of relation to AT in O2O services. Thus, we can assume that the respondents from our group may show unfamiliarity with the O2O services. Third, the attitude toward $\mathrm{O} 2 \mathrm{O}$ services has a mediating effect between the PEOU, PR, PR and the ITU.

\subsection{Managerial Implications and Limitations}

Traditional stores suffer from e-commerce more than ever. Stores may choose to differentiate with less services, then customers focus more on price and convenience over levels of services, which even strengthen on-line stores. These are the reasons why on-line retailers thrive. Research shows that even multi-channel retailers, physical stores boost sales for on-line commerce. A retailer from Europe has reported that traditional off-line store boosts about five percent of on-line sales nearby its physical stores, while out of the brick-and-mortar store area the on-line captures merely three percent. So, in reality, off-line experiences can be complementary to on-line customers. Thus, in the age of omnichannel retailing, traditional enterprises need to offer on-line store to appeal on-line customers who are in nearby. They may form higher level of trust and less risk to the on-line retailer due to its physical presence. Further, business managers may consider the role of PU and PEOU in the customers' attitude to O2O services.

Although some meaningful implications are found from this study, it has several limitations. First, the number of questionnaires is relatively small and respondents are focused on the 20 s and 30 s. Second, the TAM we applied is a 
basic but relatively simple research framework and may not be sufficient for the other variables. Third, in the future, the detailed analysis of differences by group or services will yield meaningful results.

\section{References}

Ajzen, I., \& Fishbein, M. (1975). A Bayesian analysis of attribution processes. Psychological Bulletin, 82(2). 261277

Ajzen, I. (2011). The theory of planned behavior: reactions and reflections. Psychology and Health, 26(9), $1113-$ 1127.

An, K. H., Lee, S. B., \& Suh, Y. H. (2018). An effect of O2O service users' motivation on loyalty through expectation-confirmation and satisfaction. Journal of Korean Soc Qual Management, 46(4), 923-938.

Ashraf, A. R., Thongpapanl, N., \& Auh, S. (2014). The application of the technology acceptance model under different cultural context: the case of online shopping adoption. Journal of International Marketing, 22(3), 6893.

Chi, Y. S., Kang, M. Y., Han, K. S., \& Choi, J. I. (2016). A study on the discontinuance intention on O2O commerce: with a focus on the mediating effects of perceived risk and user resistance, International Journal of $u$-and e-Service, Science and Technology, 9(2), 207-218.

Chuttur, M. (2009). Overview of the technology acceptance model: origins, developments and future directions. Indiana University, USA Sprouts. Working Papers on Information Systems, 9(37), 9-37

Davis, F. D. (1985). A technology acceptance model for empirically testing new end-user information system: Theory and results. Boston, MA: Doctoral Dissertation. Massachusetts Institute of Technology.

Davis, F. D. (1989). Perceived usefulness, perceived ease of use, and user acceptance of information technology. MIS Quarterly, 13(3), 319-340.

Davis, F. D., Bagozzi, R. P., \& Warsaw, P. R. (1989). User acceptance of computer technology: A comparison of two theoretical models, Management Science, 35(8), 982-1003.

Fishbein, M., \& Ajzen, I. (1970). The prediction of behavior from attitudinal and normative variables. Journal of Experimental Social Psychology, 6(1), 466-487.

Fornell, C., \& Larcker, D. F. (1981). Evaluating structural equation models with unobservable variables and measurement error. Journal of Marketing Research, 18(1), 39-50.

Hayes, A. F. (2017). Introduction to Mediation, Moderation, and Conditional Process Analysis: A Regression-based Approach. Emeryville, CA: Guilford Press.

Kim, N., \& Lee. D. (2016). Differences in the consumers' intention to adopt in accordance with the characteristics of car O2O services. Innovation studies, 11(1), 71-96.

Lee, Y. H., \& Jeon, I. O. (2017). The effect of characteristics of ICT-based O2O service on user satisfaction focusing on the mediating effect of user safety. Journal of Digital Convergence, 15(4), 157-169.

Lee, O. J., \& Yang, D. W. (2017). A study on the effect of O2O service quality on user satisfaction and intention of reuse. Journal of Digital Convergence, 15(6), 165-178.

Maciejewski, G. (2011). The meaning of perceived risk in purchasing decisions of the Polish customers, scientific annals of the "Alexandru Ioan Cuza" University of Iasi. Economic Sciences, volume LVIII, 280-304.

McCoy, S. Galletta, D. F., \& King, W. R. (2007). Applying TAM across cultures: the need for caution. European Journal of Information Systems, 16(1), 81-90,

Mitchell, V. W., Davies, F., Moutinho, L., \& Vassos, V. (1999). Using neural networks to understand service risk in the holiday product. Journal of Business Research, 46(2), 167-180

Oh, H. Y. (2016). Innovativeness or confidence? The effect of consumer innovativeness and self-efficacy on the acceptance and diffusion of innovative technology. International Journal of Software Engineering and Its Applications, 10(8), 117-126.

Rigby, D. K. (2011). The future of shopping. Harvard Business Review, 12(1),1-18.

Spears, N., \& Singh, S. N. (2004). Measuring attitude toward the brand and purchase intentions. Journal of Current Issues \& Research in Advertising, 26(2), 53-66.

Venkatesh, V., Morris, M. G., Davis, G. B., \& Davis, F. D. (2003). User acceptance of information technology: Toward a unified view. MIS Quarterly, 27(3), 425-478. 
Verhoef, P. C., Kannan, P. K., \& Inman, J. J. (2015). From multi-channel retailing to omni-channel retailing: Introduction to the special issue on multi-channel retailing. Journal of Retialing, 91(20), 174-181.

Wenjie, Z. \& Moon, T. (2019). The impact of O2O service influencing factors on repurchase intention in China. Proceeding of Korean MIS conference, 499-503.

Wu, J., \& Lu, X., (2013), Effects of extrinsic and intrinsic motivators on using utilitarian, hedonic, and dualpurposed information systems: a meta-analysis. Journal of the Association for Information Systems, 14(3), $153-191$.

Yim, D. S., \& Han, S. S. (2016). Omnichannel's perceived ease of use and perceived usefulness effect on omnichannel use and customer-brand relationship. Journal of Distribution Science, 14(7), 83-90.

You, J. H., \& Park, C. A. (2010). A comprehensive review of technology acceptance model researches. Entrue Journal of Information Technology, 9(2), 31-50.

Zhang, R. (2013). The development of O2O model enterprises. Logistics Engineering and management, 35(12), 127-129. 